\title{
A Knowledge Survey on Health Education of Echinococcosis Among Students - Ganzi Tibetan Autonomous Prefecture, Sichuan Province, China, 2020
}

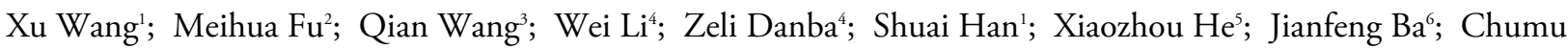 \\ Luorong7; Quzhen Jiangyang ${ }^{7}$; Yixi Luorong ${ }^{8}$; Dali ${ }^{6}$; Chunyang Li ${ }^{1}$; Dandan Shi ${ }^{1}$; \\ Yayi Guan'; Weiping $\mathrm{Wu}^{1, * ;}$; Ning Xiao ${ }^{1,9, *}$
}

\begin{abstract}
Summary
What is already known about this topic?

Previous surveys have mainly focused on how well residents and primary school students have understood the core knowledge of echinococcosis control and are limited in terms of the comprehensiveness of the knowledge category and respondents.

What is added by this report?

There were some shortcomings in related knowledge of echinococcosis among students, which showed a tendency to know methods but not the rationale. The differences among regions indicated a lack of a unified system for training educators and allocating comprehensive educational material.

What are the implications for public health practices?

The results of this study provide evidence to potentially help improve health education programs in the new phase of echinococcosis prevention and control in China.
\end{abstract}

Health education (HE) is considered an essential component of the control program for echinococcosis (1). In this study, a questionnaire survey was conducted among 2,075 junior high school students in Ganzi Tibetan Autonomous Prefecture to evaluate their knowledge regarding echinococcosis. The overall passing rate of students, i.e., passing the knowledge threshold required by the questionnaire, was $82.89 \%$. The students had good knowledge of echinococcosis control, prevention, and treatment, but many were unacquainted with the risks and theoretical details of echinococcosis. The differences in awareness about echinococcosis knowledge among students from different regions were significant, and there were clear differences between counties and between schools. The results support the formulation and adjustment of corresponding HE programs that were based on local echinococcosis prevention and control stages and characteristics. The results also encourage the establishment of a unified echinococcosis HE system, the launching and promotion of various forms of pilot HE programs, and the application of a gradual and dynamic education model for local students.

Echinococcosis is a public health problem that seriously threatens human health and restricts economic development (2). It is widespread in pastoral and semi-pastoral areas in western China, of which Ganzi is an important endemic area with a prevalence of $1.05 \%$ in humans (3). The echinococcosis prevention and control in Sichuan has experienced 4 different periods since 1980 and the basic goal of control was achieved by 2019; educational strategies matching the conditions of different times provided a key impetus in this accomplishment (4). Especially for students, it is valuable if $\mathrm{HE}$ can be efficiently accepted, and thus, not only promote changes in behavior with positive effects, but also be spread to families and family-based communities (5).

From September to October 2020, we conducted a questionnaire survey on the knowledge of echinococcosis in Ganzi, relying on the Ganzi Workstation for Echinococcosis of China CDC (6). Considering various factors such as geographical location $(\mathrm{GL})$, production mode (PM), economic level (EL), and total population (TP) of 18 counties in Ganzi (7), we selected Shiqu County (GL: north, PM: mainly husbandry, EL: low, TP: 104,600), Daofu County (midlands, semi-agricultural and semihusbandry, middle, 55,997), and Daocheng County (south, mainly agriculture and tourism, high, 31,678) as representative counties. Note that Daofu County is one of the five national-level comprehensive intervention areas of echinococcosis in Sichuan Province and that a demonstration project focusing on 
the children's HE of echinococcosis was launched here, meaning various activities were implemented and extended to middle schools before this survey (8). All eighth graders from these counties were included in the survey. To ensure authenticity, the participants' tests were administered closed-book and independently. Microsoft Office Excel 2016 (version 16.0.4266.1001, Microsoft Corporation, Redmond, US), EpiData (version 3.1, EpiData Association, Odense, Denmark) and SPSS Statistics (version 22.0, IBM Corporation, Armonk, US) were used for statistical analysis. The Hiplot website based on $\mathrm{R}$ language script or function was used for plotting (https://hiplot.com.cn).

Of the 2,190 questionnaires collected, 2,075 $(94.75 \%)$ were considered valid. Among these, 1,720 were considered as passing (passing rate $[\mathrm{PR}]=82.89 \%)$, with at least 18 of 30 questions $(60 \%)$ correct. The median score (MS) was 22 points (one point for each question). The age of the 8 th graders ranged from 11 to 21 years in the surveyed areas, and the PR and MS among different age groups showed statistical significance, both decreasing with age (Table 1). The item with the highest awareness rate (AR), i.e., answering the question correctly, was Q1, of which the correct answer was "Yes" to the question "Humans and livestock are infected with echinococcosis mainly through contact with infected dogs," while the lowest was Q30 "Echinococcosis is a category C infectious disease in Law of the People's Republic of China on prevention and control of infectious diseases (Yes)." In some of the key questions related to infection, control and prevention, and treatment (e.g., Q4, Q5, Q10, Q12, and Q16), the students' answers did not reach or just reached passing levels (Table 2). The PR of type 3 questions (Control \& Prevention) was the highest at $90.41 \%$. The other types of questions in descending order of PR were types 2 (Treatment), 5 (Assistance policies), 1 (Infection), 4 (Risks), and 6 (Theoretical knowledge) (Table 2). The students had good knowledge of the infection, treatment, and assistance policies but an insufficient understanding of echinococcosis risks, and an even worse awareness of theoretical knowledge.

We statistically analyzed the students' answers to each question. The results showed that the differences in AR of all 30 questions were statistically significant. The students of Daofu County performed the best, with the highest AR of 21 questions (Figure 1A), and

TABLE 1. Passing rate and median score of echinococcosis knowledge survey among eighth graders in Ganzi Prefecture in autumn, 2020.

\begin{tabular}{|c|c|c|c|c|c|c|c|}
\hline Characteristic & Group & $\begin{array}{c}\text { No. of } \\
\text { surveyed }\end{array}$ & $\begin{array}{l}\text { No. of } \\
\text { passing }\end{array}$ & $\begin{array}{l}\text { Passing rate*, \% } \\
(95 \% \mathrm{Cl})\end{array}$ & Test $^{\dagger}$ & $\begin{array}{c}\text { Median of score } \\
\text { with interquartile } \\
\text { range }^{\S}\end{array}$ & Test ${ }^{\pi}$ \\
\hline \multirow{2}{*}{ Sex } & Male & 888 & 737 & $83.00(80.52-85.47)$ & \multirow{2}{*}{$\begin{aligned} X^{2} & =0.120 \\
P & >0.05\end{aligned}$} & $22(19,25)$ & \multirow{2}{*}{$\begin{array}{c}Z=-0.350, P>0.05 \text { (Wilcoxon } \\
\text { Signed Rank test) }\end{array}$} \\
\hline & Female & 1,187 & 983 & $82.81(80.67-84.96)$ & & $22(19,25)$ & \\
\hline \multirow{5}{*}{ Age (years) } & $\leq 13$ & 265 & 226 & $85.28(81.02-89.55)$ & \multirow{5}{*}{$\begin{array}{c}X^{2}=26.053 \\
P<0.001^{* *} \\
X_{\text {Trend }}^{2}=17.318 \\
P<0.001\end{array}$} & $23(20,25)$ & \multirow{5}{*}{$\begin{array}{c}\mathrm{H}=31.134, P<0.001^{\dagger \dagger} \\
(\text { Kruskal-Wallis test); } \\
\mathrm{R}=-0.098, P<0.001 \text { (Pearson } \\
\text { correlation analysis); }\end{array}$} \\
\hline & 14 & 637 & 542 & 85.09 (82.32-87.85) & & $22(20,25)$ & \\
\hline & 15 & 602 & 487 & $80.90(77.76-84.04)$ & & $22(19,24)$ & \\
\hline & 16 & 367 & 302 & $82.29(78.38-86.19)$ & & $22(18,24)$ & \\
\hline & $\geq 17$ & 204 & 143 & $70.10(63.82-76.38)$ & & $21(18,24)$ & \\
\hline \multirow{2}{*}{ Nationality } & Tibetan & 2,063 & 1,710 & $82.89(81.26-84.51)$ & \multirow{2}{*}{$\begin{array}{c}X^{2}=0.002 \\
P>0.05\end{array}$} & $22(19,25)$ & \multirow{2}{*}{$\begin{array}{c}Z^{2}=-0.700 \\
P>0.05 \text { (Wilcoxon Signed Rank } \\
\text { test) }\end{array}$} \\
\hline & Others & 12 & 10 & $83.33(62.25-100.00)$ & & $23(20,25)$ & \\
\hline Total & & 2,075 & 1,720 & $82.89(81.27-84.51)$ & & $22(19,25)$ & \\
\hline
\end{tabular}

Abbreviations: $\mathrm{Cl}=$ Confidence interval.

* It was considered as passing when it had at least 20 correct answers.

$\dagger$ The chi-squared $\left(x^{2}\right)$ tests were used to infer the significance levels between passing rates.

$\S$ Students' test scores were not considered to be normal distribution after the normality tests were performed; therefore, medians were used for data descriptions.

${ }^{\pi}$ Correspondingly, because the scores did not conform to the normal distribution, the nonparametric tests were used for statistical analyses.

${ }^{* *}$ The post-hoc pairwise tests for passing rates of all age groups were performed, there were no significant differences of any pair between each age groups $\leq 13$ years, 14 years, 15 years, 16 years, but the differences of passing rates between these groups and group $\geq 17$ years were statistically significant. $P$ values were adjusted by Bonferroni correction and compared with 0.05 level.

${ }^{\mathrm{t \dagger}}$ The post-hoc pairwise tests for scores of all age groups were performed, except that there were significant differences within 3 pairs: between age group $\leq 13$ years and 15 years, between $\leq 13$ years and 16 years, and between $\leq 13$ years and $\geq 17$ years, there were no statistically significances of pairwise comparison between the other paired age groups. $P$ values were adjusted by Bonferroni correction and compared with 0.05 level. 
TABLE 2. Awareness rate of answering questions correctly and passing rate for categories of questions regarding echinococcosis knowledge survey among eighth graders in Ganzi Prefecture in Autumn, 2020.

\begin{tabular}{|c|c|c|c|c|c|}
\hline Type & Question (answer) & $\begin{array}{l}\text { No. of } \\
\text { known }\end{array}$ & $\begin{array}{l}\text { Awareness rate, } \% \\
(95 \% \mathrm{Cl})\end{array}$ & $\begin{array}{c}\text { No. of } \\
\text { passing* }\end{array}$ & $\begin{array}{l}\text { Passing rate, } \% \\
(95 \% \mathrm{Cl})\end{array}$ \\
\hline \multirow{5}{*}{$\begin{array}{l}\text { Type 1- } \\
\text { infection }\end{array}$} & $\begin{array}{l}\text { Q01. Humans and livestock are infected with echinococcosis } \\
\text { mainly through contact with infected dogs. (Yes) }\end{array}$ & 2,020 & $97.35(96.66-98.04)$ & \multirow{5}{*}{1,729} & \multirow{5}{*}{$83.33(81.72-84.93)$} \\
\hline & $\begin{array}{l}\text { Q02. Infected livestock can transmit echinococcosis directly to } \\
\text { humans. (No) }\end{array}$ & 916 & $44.14(42.01-46.28)$ & & \\
\hline & $\begin{array}{l}\text { Q03. There is a risk of echinococcosis infection in all people in } \\
\text { the endemic area. (Yes) }\end{array}$ & 1,635 & $78.80(77.04-80.55)$ & & \\
\hline & Q04. Echinococcosis can spread from person to person. (No) & 1,442 & $69.49(67.51-71.48)$ & & \\
\hline & $\begin{array}{l}\text { Q05. Patients with echinococcosis will not recur or be } \\
\text { reinfected after being cured. (No) }\end{array}$ & 1,221 & $58.84(56.73-60.96)$ & & \\
\hline \multirow{5}{*}{$\begin{array}{l}\text { Type 2- } \\
\text { treatment }\end{array}$} & $\begin{array}{l}\text { Q06. People in endemic areas of echinococcosis should take } \\
\text { the initiative to perform regular B-ultrasound examinations for } \\
\text { early detection and treatment. (Yes) }\end{array}$ & 1,684 & $81.16(79.47-82.84)$ & \multirow{5}{*}{1,859} & \multirow{5}{*}{$89.59(88.28-90.90)$} \\
\hline & $\begin{array}{l}\text { Q07. Treatment methods for echinococcosis include } \\
\text { medication and surgery. (Yes) }\end{array}$ & 2,001 & $96.43(95.64-97.23)$ & & \\
\hline & $\begin{array}{l}\text { Q08. Patients with echinococcosis can take albendazole for } \\
\text { treatment. (Yes) }\end{array}$ & 1,213 & $58.46(56.34-60.58)$ & & \\
\hline & $\begin{array}{l}\text { Q09. Patients should adhere to standardized medication and } \\
\text { accept follow-up management by township health centers. } \\
\text { (Yes) }\end{array}$ & 1,649 & $79.47(77.73-81.21)$ & & \\
\hline & $\begin{array}{l}\text { Q10. Patients with echinococcosis should be treated in } \\
\text { isolation. (No) }\end{array}$ & 1,271 & $61.25(59.16-63.35)$ & & \\
\hline \multirow{5}{*}{$\begin{array}{l}\text { Type 3- } \\
\text { control \& } \\
\text { prevention }\end{array}$} & $\begin{array}{l}\text { Q11. Diseased organs of livestock should be buried deep or } \\
\text { burned. (Yes) }\end{array}$ & 1,733 & $83.52(81.92-85.11)$ & \multirow{5}{*}{1,876} & \multirow{5}{*}{$90.41(89.14-91.68)$} \\
\hline & $\begin{array}{l}\text { Q12. Dog management should be strengthened, and dogs } \\
\text { should be dewormed regularly. (Yes) }\end{array}$ & 1,514 & $72.96(71.05-74.87)$ & & \\
\hline & $\begin{array}{l}\text { Q13. Dog feces should be collected and treated in a harmless } \\
\text { manner. (Yes) }\end{array}$ & 1,714 & $82.60(80.97-84.23)$ & & \\
\hline & Q14. To develop the good personal hygiene habits. (Yes) & 1,717 & $82.75(81.12-84.37)$ & & \\
\hline & $\begin{array}{l}\text { Q15. Washing hands before eating is the simplest and most } \\
\text { effective way to prevent echinococcosis. (Yes) }\end{array}$ & 1,763 & $84.96(83.43-86.50)$ & & \\
\hline \multirow{4}{*}{$\begin{array}{l}\text { Type 4- } \\
\text { risks }\end{array}$} & $\begin{array}{l}\text { Q16. Being infected with echinococcosis causes a decline in } \\
\text { physical function. (Yes) } \\
\text { Q17. The initial symptoms of the echinococcosis infection are } \\
\text { not obvious, that is why it can be easily ignored and can } \\
\text { aggravate physical trauma at the time of onset. (Yes) }\end{array}$ & 1,556 & $74.99(73.12-76.85)$ & \multirow{4}{*}{1,622} & \multirow{4}{*}{$78.17(76.39-79.95)$} \\
\hline & Q18. Echinococcosis is a lethal parasitic disease. (Yes) & 1,914 & $92.24(91.09-93.39)$ & & \\
\hline & $\begin{array}{l}\text { Q19. The epidemic of echinococcosis affects the economic } \\
\text { development of animal husbandry. (Yes) }\end{array}$ & 1,144 & $55.13(52.99-57.27)$ & & \\
\hline & $\begin{array}{l}\text { Q20. Patients and their families are impoverished due to } \\
\text { echinococcosis. (Yes) }\end{array}$ & 1,081 & $52.10(49.95-54.25)$ & & \\
\hline \multirow{5}{*}{$\begin{array}{l}\text { Type 5- } \\
\text { assistance } \\
\text { policies }\end{array}$} & $\begin{array}{l}\text { Q21. Free B-ultrasound examinations for people in epidemic } \\
\text { areas of echinococcosis. (Yes) }\end{array}$ & 1,264 & $60.92(58.82-63.02)$ & \multirow{5}{*}{1,778} & \multirow{5}{*}{$85.69(84.18-87.19)$} \\
\hline & Q22. Free medication for echinococcosis patients. (Yes) & 1,740 & $83.86(82.27-85.44)$ & & \\
\hline & $\begin{array}{l}\text { Q23. Patients can take treatment drugs at the local CDC or } \\
\text { township health centers. (Yes) }\end{array}$ & 1,801 & $86.80(85.34-88.25)$ & & \\
\hline & $\begin{array}{l}\text { Q24. To provide subsidies to patients undergoing surgical } \\
\text { treatment. (Yes) }\end{array}$ & 1,602 & $77.20(75.40-79.52)$ & & \\
\hline & $\begin{array}{l}\text { Q25. To include patients in poverty alleviation and assistance } \\
\text { targets. (Yes) }\end{array}$ & 1,084 & $52.24(50.09-54.39)$ & & \\
\hline \multirow{5}{*}{$\begin{array}{l}\text { Type 6- } \\
\text { theoretical } \\
\text { knowledge }\end{array}$} & $\begin{array}{l}\text { Q26. Livestock is the intermediate host of Echinococcus. } \\
\text { (Yes) }\end{array}$ & 1,419 & $68.39(66.38-70.39)$ & \multirow{5}{*}{1,477} & \multirow{5}{*}{$71.18(67.76-71.71)^{\dagger}$} \\
\hline & Q27. Dogs are the definitive host of Echinococcus. (Yes) & 1,613 & $77.73(75.94-79.52)$ & & \\
\hline & $\begin{array}{l}\text { Q28. Echinococcus eggs are highly resistant and can survive } \\
\text { in the natural environment for a long time. (Yes) }\end{array}$ & 1,204 & $58.02(55.90-60.15)$ & & \\
\hline & $\begin{array}{l}\text { Q29. The echinococcosis is mainly divided into } C E \text { and } A E \text { in } \\
\text { China. (Yes) }\end{array}$ & 1,416 & $68.24(66.24-70.24)$ & & \\
\hline & $\begin{array}{l}\text { of the People's Republic of China on prevention and control of } \\
\text { infectious diseases. (Yes) }\end{array}$ & 808 & $38.94(36.84-41.04)$ & & \\
\hline
\end{tabular}

Note: The post-hoc pairwise tests for passing rates of all types were performed, except that there were no statistical significances between Type 1 and 5 , and between Type 2 and 3 , there were significant differences between the other paired types. $P$-values were adjusted by Bonferroni correction and compared with 0.05 level.

Abbreviations: $\mathrm{Cl}=$ confidence interval; $\mathrm{CE}=$ cystic echinococcosis; $\mathrm{AE}=$ alveolar echinococcosis.

* In each type, it was considered as passing to answer 3 or more questions correctly.

$\dagger$ The chi-squared $\left(X^{2}\right)$ test of passing rate of 6 types was performed and the result was: $X^{2}=396.228, P<0.001$. 


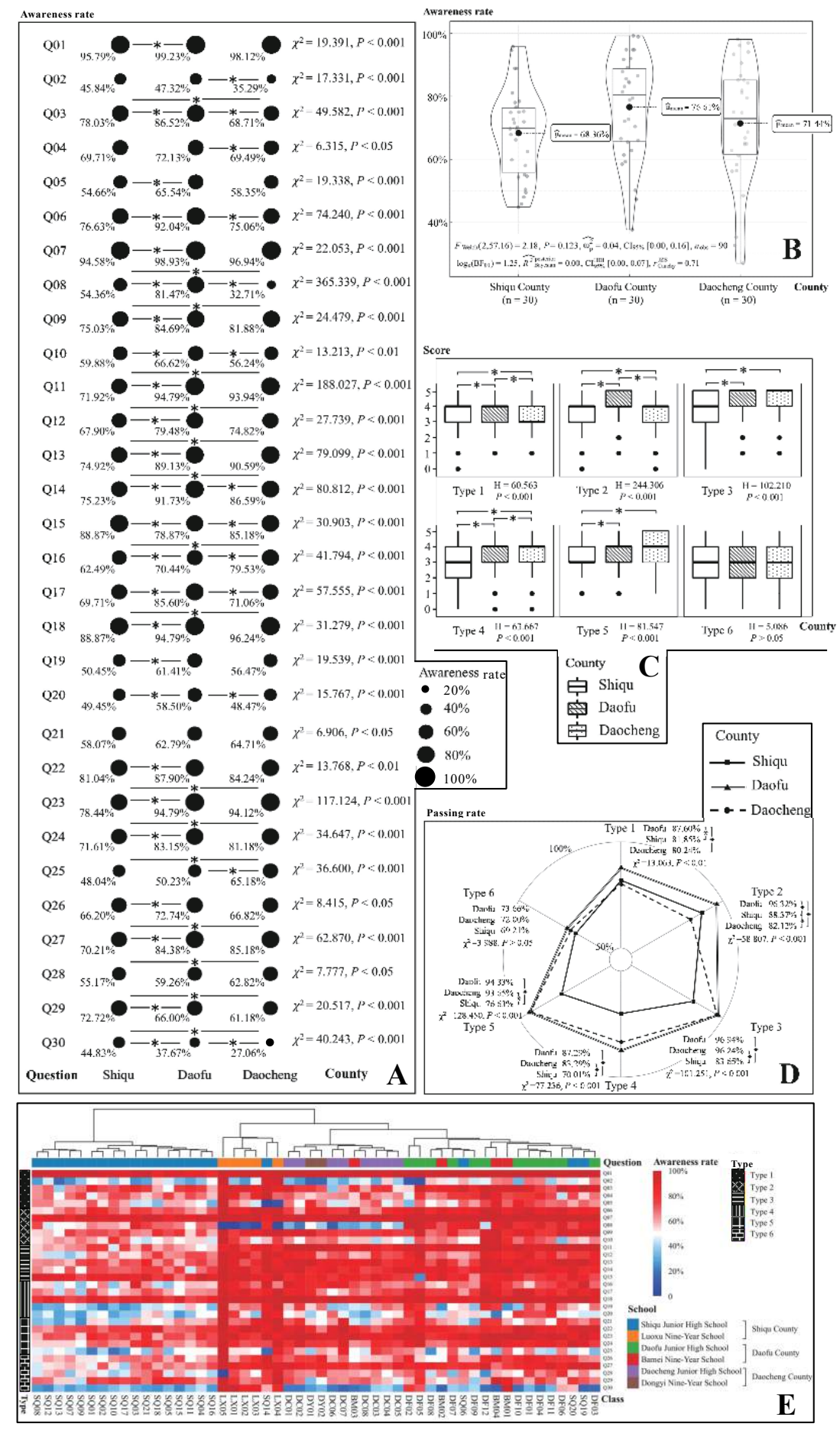

FIGURE 1. Comparison of awareness rate, score and passing rate of echinococcosis knowledge survey $(n=2,075)$ among eighth graders of Shiqu, Daofu, and Daocheng counties in Ganzi Prefecture in autumn 2020. (A) A matrix-bubble figure for awareness rate of 30 questions with the Pearson Chi-Square $\left(X^{2}\right)$ test among three counties. (B) A stats-violin figure shows the distribution of awareness rate among the three counties. (C) A box-scatter figure for the median score of the six types of questions with Kruskal-Wallis H-test among three counties. (D) A radar-chart figure shows the qualified rate of the six types of questions among three counties. (E) The inter-heatmap was drawn to show the clustering of awareness rate from 52 classes based on Ward's minimum variance method (Ward. D2).

* In Graph (A), (C), and (D), it indicates that there was a statistical significance between two counties after the post-hoc tests were performed, $P$ values were adjusted by Bonferroni correction and compared with 0.05 level. In Graph (B), the $Y$-axis and $\mathrm{X}$-axis indicate the range and density, respectively, of the awareness rate. 
the highest average AR (76.61\%) (Figure 1B). However, Shiqu County was the most evenly distributed county in the distribution of AR level between highest and lowest, followed by Daofu County, while Daocheng County had the largest gap (Figure 1B). Comparing the scores for each type among 3 counties, Daofu County performed better in types 1, 2, 3 and 4 according to their MS (the full score was 5 points per type); Daocheng County was better in types 3 and 5; and Shiqu County was better in type 1 (Figure 1C). Daofu County ranked the highest in terms of PR in all types and achieved more than $90 \% \mathrm{PR}$ in types 2, 3, and 5 (Figure 1D). Overall, Daofu County showed obvious advantages over the other two counties in all aspects. Moreover, based on the AR level of 30 questions, 52 classes of 6 schools from 3 counties were clustered into 4 branches on a tree-structured clustering framework, and the classes could basically be mapped to the branches of their corresponding school or county by the differentiation on awareness of each item (Figure 1E).

\section{DISCUSSION}

The following characteristics of the current HE were derived from the above results. 1) There were differences in individual awareness rates in a group; for example, older students had poor responses in the same grade. 2) There were differences in students' awareness of different types of knowledge. There was a tendency to know how to do things but not to know why. 3) There were some key issues in the HE processes that might have been ignored or misunderstood by the students. For example, some students thought that echinococcosis could be transmitted human-to-human because they were not aware of the biological life cycle of Echinococcus. 4) The unevenness of the students' awareness of echinococcosis among different regions should be noted. In this study, the highest overall scoring students from Daofu County indicated that the specific HE model did have a positive impact. 5) The distribution difference and preference clustering of AR among regions and schools revealed the lack of a unified and comprehensive echinococcosis-related HE system.

In addition, we compared the results of other surveys from primary school students (9-10). The high AR of core knowledge was similar to that of junior high school students in this survey, assessed through questions such as Q01, Q11, Q13, and Q15. This showed that some key knowledge points have been strengthened and fixed in the student population. However, we also found that the answers were not satisfactory for some questions, especially regarding the risks and theoretical knowledge of echinococcosis. Junior high school students generally had higher levels of education due to more years in schools and were likely better able to understand related information than primary school students. Therefore, the breadth and depth of previous HE were limited and lacked some coverage for junior high school students.

We put forward the following suggestions. First, unified teaching materials should be formulated or designated. This requires the cooperation of health and education departments to launch educational materials suitable for students and provide education at the corresponding acceptance levels for different age groups. Second, school health educators should receive more professional and comprehensive training to have an in-depth understanding of echinococcosis. This way, teachers can bring their personal initiative into lessons and pay attention to the disadvantaged members with insufficient knowledge of echinococcosis. Third, relevant pilot testing and promotion strategies should be encouraged. Daofu County's educational system is a model that attracts attention and has adopted a variety of educational methods to enable students to understand knowledge and accept behavior changes. Fourth, a regular health education evaluation is necessary to help policymakers or program planners to correct the gaps in the current work.

This study was subject to some limitations. First, the study focused on eighth grade students and did not involve other grades; therefore, the current levels of echinococcosis awareness among junior high school students needs further investigation. Second, due to the large number of respondents, the length of the study period was extended as the survey of Shiqu County was carried out first in early September, and Daofu County was last to be surveyed in mid-October. Therefore, the variation in survey timing may impact the results.

The health education strategy of spreading echinococcosis prevention and control knowledge to the surrounding population, starting with students as the focal point, is helpful to realize the bidirectional combination of infection source control and population active prevention. This study found some problems in the current $\mathrm{HE}$ project of echinococcosis and provided some targeted suggestions. However, the improvement of the HE program is still a long, 
gradual, and localized process that needs more attention and effort.

Conflicts of interest: No conflicts of interest.

Acknowledgements: Wei Xu and Ma Shuo (School of Life Science, East China Normal University).

Funding: Supported by the Research Projects of Shanghai Municipal Health Commission (Grant No. 2021Y0213).

doi: $10.46234 / \mathrm{ccdcw} 2022.005$

\# Corresponding authors: Weiping Wu, wuwp@nipd.chinacdc.cn; Ning Xiao, xiaoning@nipd.chinacdc.cn.

\begin{abstract}
${ }^{1}$ National Institute of Parasitic Diseases, Chinese Center for Diseases Control and Prevention (Chinese Center for Tropical Diseases Research); NHC Key Laboratory of Parasite and Vector Biology; WHO Collaborating Centre for Tropical Diseases; National Center for International Research on Tropical Diseases, Shanghai, China; 2 Shanghai Municipal Center for Disease Control and Prevention, Shanghai, China; ${ }^{3}$ Sichuan Center for Disease Control and Prevention, Chengdu, Sichuan, China; ${ }^{4}$ Ganzi Tibetan Autonomous Prefecture Center for Disease Control and Prevention, Ganzi, Sichuan, China; ${ }^{5}$ National Institute of Viral Diseases Control and Prevention, Chinese Center for Diseases Control and Prevention, Beijing, China; ${ }^{6}$ Shiqu County Center for Disease Control and Prevention, Ganzi, Sichuan, China; ${ }^{7}$ Daofu County Center for Disease Control and Prevention, Ganzi, Sichuan, China; ${ }^{8}$ Daocheng County Center for Disease Control and Prevention, Ganzi, Sichuan, China; ${ }^{9}$ The School of Global Health, Chinese Center for Tropical Diseases Research, Shanghai Jiao Tong University School of Medicine, Shanghai, China.
\end{abstract}

Submitted: September 28, 2021; Accepted: December 17, 2021

\section{REFERENCES}

1. Eckert J, Gemmell MA, Meslin F, Pawlowski ZS. WHO/OIE manual on echinococcosis in humans and animals: a public health problem of global concern. https://www.who.int/publications/i/item/929044522X. [2021-1-25].

2. Fu MH, Wang X, Han S, Guan YY, Bergquist R, Wu WP. Advances in research on echinococcoses epidemiology in China. Acta Trop 2021; 219:105921. http://dx.doi.org/10.1016/j.actatropica.2021.105921.

3. He W, Wang LY, Yu WJ, Zhang GJ, Zhong B, Liao S, et al. Prevalence and spatial distribution patterns of human echinococcosis at the township level in Sichuan Province, China. Infect Dis Poverty 2021;10 (1):82. http://dx.doi.org/10.1186/s40249-021-00862-z.

4. Wang Q, Zhang GJ, Yu WJ, Liao S, He W, Huang Y, et al. From epidemic to preliminary control: retrospective review of echinococcosis prevention and control in the past 40 years. Chin J Parasitol Parasit Dis 2021;39(2):133 - 8. http://dx.doi.org/10.12140/j.issn.1000-7423. 2021.02.001. (In Chinese).

5. Masala S, Parodi P. Health education and formation: essential tools into the echinococcosis/hydatidosis prevention programs. Parassitologia 2004;46(4):393-6. https://pubmed.ncbi.nlm.nih.gov/16044698/.

6. Tian T, Han S, Xue CZ, Wang X, Yang SJ, Zhong B, et al. A platform to improve Echinococcosis control in Tibetan populations - Sichuan Province, China, 2015-2020. China CDC Wkly 2021;3(5):94-7. http://dx.doi.org/10.46234/ccdcw2021.024.

7. Statistics Bureau of Ganzi Tibetan Autonomous Prefecture, Ganzi Investigation Team of the National Bureau of Statistics. Ganzi Statistical Yearbook -2020. Kangding: Editorial Dapartment of Ganzi Statistical Yearbook. 2021. http://tjj.gzz.gov.cn/gzztjj/tjsj/202103/ 89765460146747a09fdd1d8b6378cd5c.shtml. [2021-3-4]. (In Chinese).

8. Sichuan Center for Disease Control and Prevention. "Thirteenth FiveYear Plan" and 2020 work summary, and 2021 work schedule of Sichuan Center for Disease Control and Prevention. http://www. sccdc.cn/View.aspx?id=24085. [2021-1-25]. (In Chinese).

9. Zhang GJ, Wang Q, Liu Y, Zhong B, Danba ZL, Luorong CM, et al. Exploration of a health education model and evaluation of its effect on echinococcosis control among students in Tibetan community, Sichuan Province. Chin J Parasitol Parasit Dis 2021;39(2):145 - 9. http://dx. doi.org/10.12140/j.issn.1000-7423.2021.02.003. (In Chinese).

10. Xiao N, Zhou ZJ, Chen XW, Zeng YZ, Wang ZY, Lei Y, et al. Assessment of health education against echincococcosis in Tibetan region of Sichuan Province, China. Chin J Parasitol Parasit Dis 2012;30(1):6-11. http://d.wanfangdata.com.cn/periodical/zgjscxyjscbzz 201201003. (In Chinese). 